\title{
How to Control Component Ratio of Conducting Polymer Blend for Organic Photovoltaic Devices by Annealing
}

\author{
Bobins Augustine and Tapio Fabritius \\ Optoelectronics and Measurement Techniques Laboratory, Department of Electrical Engineering, University of Oulu, \\ Erkki Koiso-Kanttilan Katu 3, 90570 Oulu, Finland \\ Correspondence should be addressed to Bobins Augustine; baugusti@ee.oulu.fi
}

Received 6 August 2015; Revised 13 November 2015; Accepted 7 December 2015

Academic Editor: Věra Cimrová

Copyright (C) 2015 B. Augustine and T. Fabritius. This is an open access article distributed under the Creative Commons Attribution License, which permits unrestricted use, distribution, and reproduction in any medium, provided the original work is properly cited.

There are various conducting polymer blends which are used as hole transporting layers (HTL) in organic photovoltaic devices (OPV). The electrical performance of these conducting polymer blends depends crucially on its surface compositions and morphology. In this paper, we studied poly(3,4-ethylenedioxythiophene)-poly(styrenesulfonate) or PEDOT:PSS as an example of the HTL conducting polymer blends used in OPV. We have investigated the effect of annealing PEDOT:PSS in different atmospheres such as vacuum, $\mathrm{N}_{2}$, and air at different temperatures. It was found that the component ratio of the polymer blend is changing with annealing temperature and atmosphere. PSS/PEDOT ratio was found to have clear influence on the electrical performance of the material. In practice, we found that annealing can be used as a method to control component ratio of the HTL conducting polymer blend to achieve better electrical performance in OPV devices. The component ratio changes of the polymer with annealing were understood by X-ray photoelectron spectroscopy (XPS). Annealing in $\mathrm{N}_{2}$ atmosphere at $220^{\circ} \mathrm{C}$ for 1 hour gave best electrical performance for the polymer and the PSS/PEDOT ratio at that condition was close to 1.1, while the initial ratio was 2.5. Optimizing HTL layer by simple conductivity measurement does not guarantee best performance in OPV since surface property changes during annealing might affect the deposition of successive active layers on top and thus final device. Thus we have optimized annealing condition of the HTL layer according to the OPV performance itself.

\section{Introduction}

Over the last decade, there has been an increased interest in the field of organic photovoltaic devices (OPV) because of their future potential as an inexpensive technology for electricity production [1]. Although there are certain limitations for these devices relating to its stability $[2,3]$, the technology is attractive due to its reduced cost. The performances of these devices strongly depend on the morphology and the structure of the constituting organic material [4, 5]. The most preferred conducting polymer blend which serves as the hole transporting layer (HTL) in OPV is poly(3,4-ethylenedioxythiophene)-poly(styrenesulfonate) or PEDOT:PSS [6]. Its properties depend on its morphology, which in turn relies on the annealing temperature and atmosphere. The PEDOT:PSS is made up of ethylenedioxythiophene (EDOT) monomers and poly(styrene sulfonic acid) (PSS). PEDOT in its pure form is insoluble in many common solvents and is infusible at normal temperatures [7, 8]. The problem of insolubility of PEDOT in usual solvents is bypassed by polymerization of PEDOT in the presence of water soluble poly(styrene sulfonic acid) (PSS) [9-11]. In PEDOT:PSS, generally the excess PSS from the colloidal solution seems to form a closed surface layer over PEDOT, which also considerably decreases the conductivity since PSS is slightly insulating and PEDOT is more conductive $[12,13]$. The PSS part of PEDOT:PSS is strongly hygroscopic and it can change its morphology depending on the atmosphere in which it is annealed [12]. The mentioned effects can influence final device performance considerably. There were certain annealing studies of PEDOT:PSS previously made by many researchers which had investigated the effect only in single atmosphere and the component variation dependence with the performance in different atmospheres was not clearly understood [14-16]. In this paper we studied PEDOT:PSS by making OPVs on top of them. The performance of 
the OPV cells containing PEDOT:PSS annealed in different atmospheres such as air, nitrogen, and vacuum was analyzed. The study was focused on finding the relation between the component variation change during annealing of PEDOT:PSS with the performance of the OSC device and thus finding the optimum condition for PEDOT:PSS in OPV with a view of achieving best device performance. The behavior changes of PEDOT:PSS under different annealing condition were further analyzed with X-ray photoelectron spectroscopy (XPS). The results of this study are equally useful in the field of conducting polymers, OPV, and organic light emitting diodes (OLED).

\section{Experimental Details}

2.1. Materials and Device Fabrication. The glass substrates with patterned indium tin oxide (ITO) stripes were supplied by Thin Film Devices, Inc. (TFD). The square glass substrates with a dimension of $6.25 \mathrm{~cm}^{2}$ were covered in the middle part with a $1.3 \mathrm{~cm}$ wide ITO stripe. The ITO thickness was $150 \mathrm{~nm}$ and had $20 \mathrm{ohm} / \mathrm{sq}$ sheet resistance. The substrates were first cleaned with acetone followed by isopropanol and methanol. Then they were plasma treated by Plasma PREEN II-862 asher (60 Watts, flow rate 4-5 SCFM), for 1 minute before PEDOT:PSS deposition.

In this work, the poly(3,4-ethylenedioxythiophene)poly(styrenesulfonate) under study was PH500. It was supplied by Heraeus. It was deposited by spin coating with a spin speed of 6700 RPM in normal room atmosphere. The three different batches of substrates were subsequently dried under respective atmospheres such as air, nitrogen, and vacuum for 1 hour each at temperature ranging from $70^{\circ} \mathrm{C}$ to $270^{\circ} \mathrm{C}$ at $50^{\circ} \mathrm{C}$ intervals. After drying treatment of the PH500, the samples were immediately transferred to the glovebox and the active layer was spin coated on top.

The active layer was a blend of poly(3-hexylthiophene2,5-diyl) (P3HT) which was supplied by Sigma Aldrich and phenyl- $\mathrm{C}_{61}$-butyric acid methyl ester $\left(\mathrm{PC}_{60} \mathrm{BM}\right)$ was supplied by Nano $C$. It is blended by making the solution in the ratio 1: 0.8 with a concentration of $30 \mathrm{mg} / \mathrm{mL}$, dissolved in 1,2dichlorobenzene. The solution was stirred at $55^{\circ} \mathrm{C}$ overnight. The active layer blend was spin coated inside a glovebox at 450 RPM for 2 minutes on top of the different batches of substrates spin coated with PH500 [17]. After drying the sample for 1 hour at room temperature in the nitrogen-filled glovebox, the film was annealed at $150^{\circ} \mathrm{C}$ for 30 minutes [18]. Annealing parameter of the active layer was kept the same for the three different batches of the PH500 coated substrates. After that a $0.6 \mathrm{~nm}$ lithium fluoride layer and then $120 \mathrm{~nm}$ aluminum layers were deposited as electrodes [19]. The finished devices had an active area of $15 \mathrm{~mm}^{2}$.

2.2. Device Characterization. The photovoltaic characteristics were evaluated under Air Mass 1.5, class AAA solar simulator (Oriel Inc.) as the light source, and light intensity was calibrated to $100 \mathrm{~mW} / \mathrm{cm}^{2}$ by using a National Renewable Energy Laboratory (NREL) calibrated crystalline silicon reference cell. The measurements were done inside a nitrogen-filled glovebox. The parameters, open circuit voltage $\left(V_{\text {oc }}\right)$, short circuit current density $\left(J_{\mathrm{sc}}\right)$, fill factor $(\mathrm{FF})$, and power conversion efficiency (PCE) were obtained from corresponding current density- $(J-)$ voltage $(V)$ curves. For average measurements, 15 solar cells with an active area of $15 \mathrm{~mm}^{2}$ each were taken for each measurement. The component variation of PEDOT and PSS in various hole transporting layers under different annealing condition was analyzed by using X-ray photoelectron spectroscopy (XPS). The XPS experiments were performed by the system Thermo Fisher Scientific ESCALAB 250Xi. Avantage software was used for the analysis of the data and background subtraction. Monochromatic $\mathrm{Al} \mathrm{K} \alpha$ X-rays $(1486.68 \mathrm{eV})$ were utilized for excitation and detection area was set to $900 \mu \mathrm{m}$ in diameter. The detector mode was in Constant Analyzer Energy (CAE). Survey scan pass energy was $150 \mathrm{eV}$ with step size of $1 \mathrm{eV}$. The chemical states of compounds were identified and quantified by analyzing the photoelectron transitions of $S 2 p$.

\section{Results and Discussion}

3.1. J-V Characteristics of PH500 Based OPV Devices. In order to find the right annealing point at which the PEDOT:PSS give best performance, the layer was annealed within a range of different temperatures and in different atmospheres as in Figure 1.

The plots in Figure 1 show the average variation of the parameters such as $J_{\mathrm{sc}}, V_{\mathrm{oc}}, \mathrm{FF}$, and PCE of the PH500 based $\mathrm{OPV}$ devices due to annealing of $\mathrm{PH} 500$ layer from $70^{\circ} \mathrm{C}$ to $270^{\circ} \mathrm{C}$ in the three different atmospheres.

In Figure 1(a), the case of the device for which PH500 layer was annealed in nitrogen atmosphere, the average $J_{\mathrm{sc}}$ value was $5.3 \mathrm{~mA} / \mathrm{cm}^{2}$ at $70^{\circ} \mathrm{C}$, and it increased slightly up to $5.61 \mathrm{~mA} / \mathrm{cm}^{2}$ at $170^{\circ} \mathrm{C}$. Following this, there was a drastic increase in the value till $220^{\circ} \mathrm{C}$ which reached up to $7.43 \mathrm{~mA} / \mathrm{cm}^{2}$, suggesting better morphology of the PH500 layer at that point; after this the value sharply decreases to $5.89 \mathrm{~mA} / \mathrm{cm}^{2}$. In the case of devices that were annealed in a vacuum atmosphere, the initial $J_{\mathrm{sc}}$ value was $5.83 \mathrm{~mA} / \mathrm{cm}^{2}$, which is greater than the corresponding value in a nitrogen atmosphere; the value increases up to $170^{\circ} \mathrm{C}$ to $7.33 \mathrm{~mA} / \mathrm{cm}^{2}$, which was slightly less than that in the nitrogen atmosphere and beyond this temperature the value dropped to $270^{\circ} \mathrm{C}$ which was $6.34 \mathrm{~mA} / \mathrm{cm}^{2}$. For devices annealed in air, the initial $J_{\text {sc }}$ at $70^{\circ} \mathrm{C}$ was close to the device in a vacuum atmosphere and higher than that of devices in a nitrogen atmosphere; the values were almost constant up to $170^{\circ} \mathrm{C}$, which was $6.06 \mathrm{~mA} / \mathrm{cm}^{2}$, but showed a rapid decrease in value after this temperature. By taking into account all these observations for $J_{\mathrm{sc}}$, the nitrogen atmosphere showed better values for $J_{\mathrm{sc}}$ at $220^{\circ} \mathrm{C}$ which was the highest among the other atmospheres. In Figure 1(b), the average FF showed closer values at $220^{\circ} \mathrm{C}$ in vacuum and air.

From the plot in Figure 1(c), for devices annealed in air, the $V_{\text {oc }}$ value was almost constant from $70^{\circ} \mathrm{C}$ to $270^{\circ} \mathrm{C}$ but the values were lower than that for nitrogen annealed samples but higher than that for vacuum annealed samples. In Figure 1(d), 


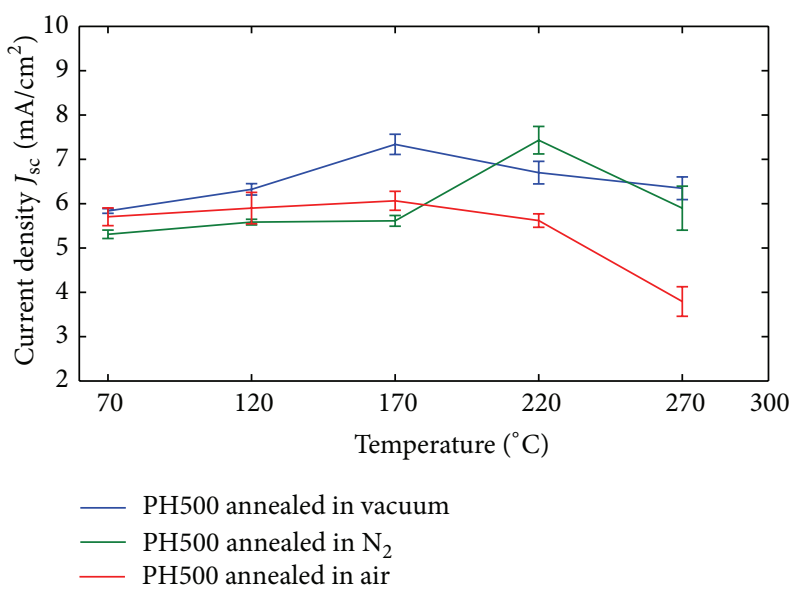

(a)

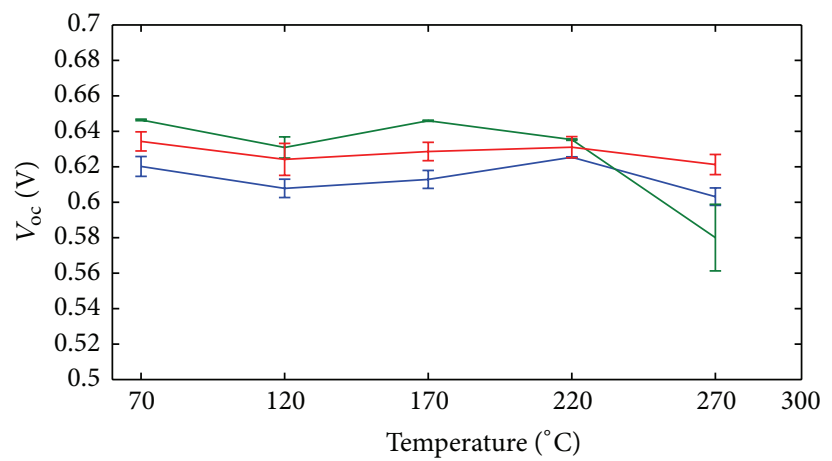

- PH500 annealed in vacuum
- PH500 annealed in $\mathrm{N}_{2}$
- PH500 annealed in air

(c)

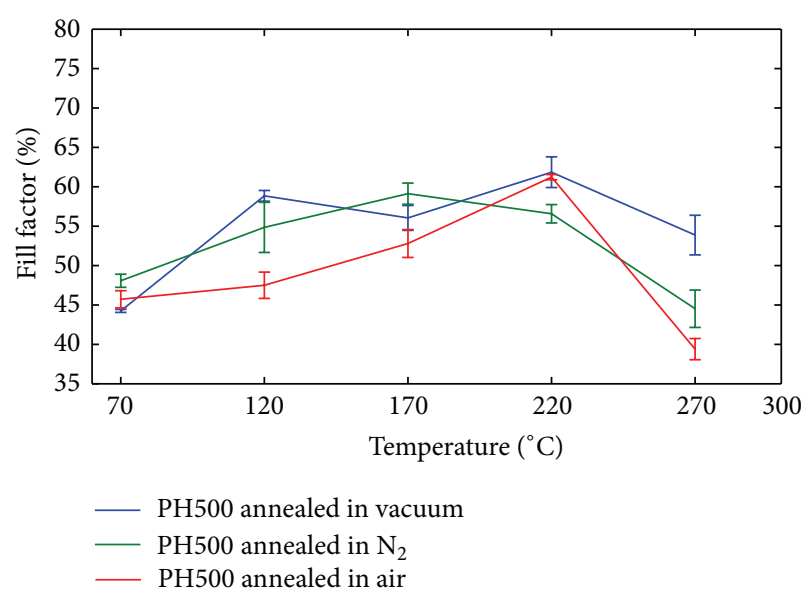

(b)

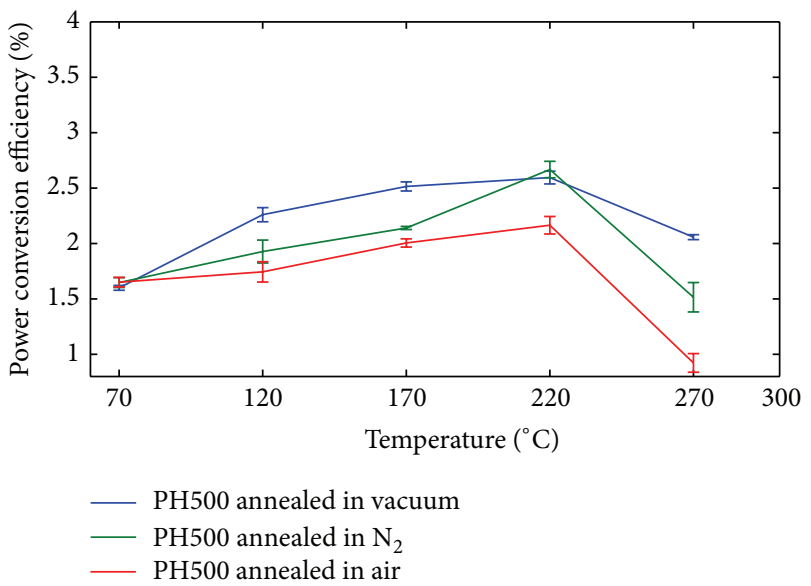

(d)

FIGURE 1: The average variation of photovoltaic parameters of PH500 based devices with temperatures in three different atmospheres.

the power conversion efficiencies for vacuum annealed samples are higher till $170^{\circ} \mathrm{C}$ compared to nitrogen annealed and air annealed samples. But when the annealing temperature reaches $220^{\circ} \mathrm{C}$, the average PCE values of samples annealed in nitrogen sharply increase to its highest value of $2.67 \%$ and statistically are almost the same as the devices in a vacuum atmosphere at the same temperature. The best PCE value for air annealed sample was obtained at $220^{\circ} \mathrm{C}$ which was lower compared to other atmospheres and was about $2.17 \%$. The values are also closer to other groups [20].

From Table 1, its evident that the best atmosphere for annealing of PH500 is in $\mathrm{N}_{2}$.

3.2. Analysis of Behavioral Changes due to Annealing of PH500. Figure 2 shows the variation of PEDOT and PSS content in PH500 analysed with XPS technique for samples annealed at their optimum temperature which was $220^{\circ} \mathrm{C}$.

There are sulfur atoms in both PEDOT and PSS, but their binding energy peaks are different and hence the individual component content of PEDOT and PSS can be easily distinguished by the XPS analysis. It was reported that the sulfur atom peak $S 2 p$ in PEDOT has lower binding energy [21]. The $\mathrm{S} 2 \mathrm{p}$ peaks at $164.6 \mathrm{eV}$ and $163.4 \mathrm{eV}$ correspond to

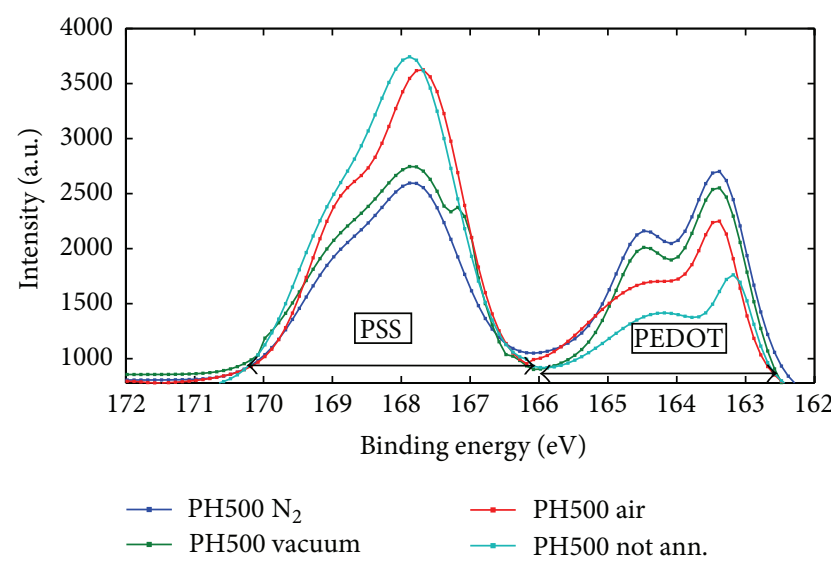

FIGURE 2: S 2p XPS peaks of PH500 samples annealed in air, $\mathrm{N}_{2}$, and vacuum at $220^{\circ} \mathrm{C}$ and also PH500 which is not annealed.

PEDOT component. The peaks at $169 \mathrm{eV}$ and $167.8 \mathrm{eV}$ correspond to sulfur component in PSS [21]. By understanding the component of PEDOT and PSS with respect to their corresponding sulfur peaks, the component variation can be analyzed. 
TABLE 1: Average photovoltaic properties of PH500 in different atmospheres at optimum annealing temperature.

\begin{tabular}{lccccc}
\hline \multicolumn{2}{l}{ Anneal. atm. $V_{\text {oc }}(\mathrm{V})$} & $\mathrm{FF}(\%)$ & $\begin{array}{c}J_{\mathrm{sc}} \\
\left(\mathrm{mA} / \mathrm{cm}^{2}\right)\end{array}$ & $\begin{array}{c}\text { PCE } \\
(\%)\end{array}$ & $\begin{array}{c}\text { Opt. ann. } \\
\text { temp. }\left({ }^{\circ} \mathrm{C}\right)\end{array}$ \\
\hline Vacuum & 0.625 & 61.85 & 6.7 & 2.58 & 220 \\
$\mathrm{~N}_{2}$ & 0.635 & 56.57 & 7.43 & 2.67 & 220 \\
Air & 0.631 & 61.2 & 5.62 & 2.17 & 220 \\
\hline
\end{tabular}

The variation of component of PEDOT:PSS occurs during the thermal treatment and it is relating to the structure of PEDOT:PSS. PEDOT mixed with PSS forms a colloidal solution in water consisting of random coil entanglement of hydrophilic insulating PSS chains with attached hydrophobic conductive PEDOT oligomers. The PSS shell swelled with moisture content also forms shells around the conductive PEDOT grains [22], and when annealed at the optimum temperature, the PSS shell shrinks and exposes more conductive PEDOT grains and can also loose the excess PSS content. In effect it increases the density of PEDOT content at the surface, thus reflecting in the component ratio measured by XPS.

The PEDOT and PSS components vary with the annealing and thermal exposure changed the amount of constituent component. The effect of PEDOT content which is more conductive is in correlation with the current density of the device annealed in respective atmosphere and temperature. The PSS which is less conductive is reducing the conductivity and the efficiency of the device. Analysing the content concentration from each respective peak, it was found that the PEDOT content which is more conductive is higher for PH500 annealed in nitrogen. It is evident from Figure 2 that the PEDOT content is higher and PSS content reduced by annealing in both cases of $\mathrm{N}_{2}$ and vacuum compared with air. The PCE values of the devices obtained in vacuum are closer to the performance in $\mathrm{N}_{2}$. This is the clear indication that the lack of moisture plays important role in enhancing device performance. The nitrogen flow is also efficient in removing the trapped moisture content.

It was reported that the PSS forms insulating shell around PEDOT in the structure of PEDOT:PSS and annealing at higher temperature can result in the shrinking of the component by evolving moisture content and can be the reason why the components of PSS and PEDOT vary on thermal exposure [23-26].

Annealing till $220^{\circ} \mathrm{C}$ can decrease also the water content, leading to the shrinkage of the insulating PSS shell around the conducting PEDOT grains and thus varying component content to a favourable ratio and hence improving performance. At temperature greater than $220^{\circ} \mathrm{C}$, the performance of PH500 is drastically dropped and this might be due to larger changes in the component ratio of PEDOT and PSS which might change the surface property and wetting properties which in turn might have affected the deposition on active layer on top of it and thus the performance of the device [27]. The structure PEDOT:PSS is such that the PSS surrounds the PEDOT grains as an insulative shell and when the moisture content is reduced, the PSS shrinks and exposes the conductive PEDOT on the surface [22]. This causes the increase in density of conductive PEDOT on the surface, thus leading to increased conductivity of the layer and thus reflecting the performance in the OSC devices.

The dominant reason why the performance is varying with change in atmosphere condition is based on the fact that the boiling point (BP) of the material is different in different atmospheres. In normal air atmosphere, PEDOT:PSS has BP closer to water [28]. Thus the rate of evolution of water content as well as changes in the component ratio in PEDOT:PSS layer is different in $\mathrm{N}_{2}$ as well as vacuum atmosphere in comparison with air. This can cause significant change in the morphology of the PEDOT:PSS layer and how it behaves. PEDOT mixed with PSS forms a colloidal solution in water consisting of random coil entanglement of hydrophilic insulating PSS chains with attached hydrophobic conductive PEDOT oligomers, forming conductive grains. These grains consist of PEDOT rich core surrounded by PSS rich shell. Both vacuum and nitrogen are offering inert atmosphere avoiding the chance of possible swelling by moisture. The nitrogen atmosphere seems to reduce more efficiently the PSS content than vacuum. The flow of $\mathrm{N}_{2}$ gas while the PEDOT:PSS coated samples were annealed in glovebox might be removing the trapped moisture inside the layer of the conducting polymer. This causes the polymer chains to come closer by shrinking due to the evolution of the moisture content, thus decreasing the resistance which leads to the superior performance. The factors responsible for enhanced performance in $\mathrm{N}_{2}$ atmosphere might be due to difference in BP, inert atmosphere, improved crystallinity, and role of $\mathrm{N}_{2}$ in removing trapped water content. The influence of nitrogen atmosphere might also be affecting the electrostatic interaction with the PSS chains. Also there might be wettability changes of the material due to differences in PEDOT and PSS content, since PSS is very hydrophilic and reduction in PSS part improves the wettability of the subsequent active layer which is nonpolar. The increase in the wettability also enhances the device performance.

Parallel changes in properties might also take place such as change in layer roughness, uniformity, wettability, absorbance, and crystallinity. These properties also affect the final performance of the device. But our study was focused on finding the correlation between the component ratio of PEDOT:PSS with the performance of OPV as annealed in different atmosphere.

From Figure 3, it is evident that there is strong behavioral dependence between PSS/PEDOT ratio at optimum temperature with the PCE and $J_{\mathrm{sc}}$ values measured. The PSS/PEDOT ratio should be low and close to 1.1, in order to obtain the best performance. The initial PSS/PEDOT component ratio of PH500 as specified by the supplier Heraeus Clevios is 2.5.

It can be seen from Figure 3 that the component ratio varies as in different atmosphere annealed at $220^{\circ} \mathrm{C}$. In air atmosphere, the PSS/PEDOT ratio reduces from its initial value by $26.16 \%$. In vacuum atmosphere, the reduction was by $46 \%$. In $\mathrm{N}_{2}$ atmosphere, the PSS/PEDOT ratio reduced by $54.8 \%$. This was an interesting observation since the $\mathrm{PSS} / \mathrm{PEDOT}$ ratio varies differently although it is annealed at the same temperature and duration. Hence the finding clearly gives the information that the atmosphere has significant influence on the electrical properties of PEDOT:PSS during 


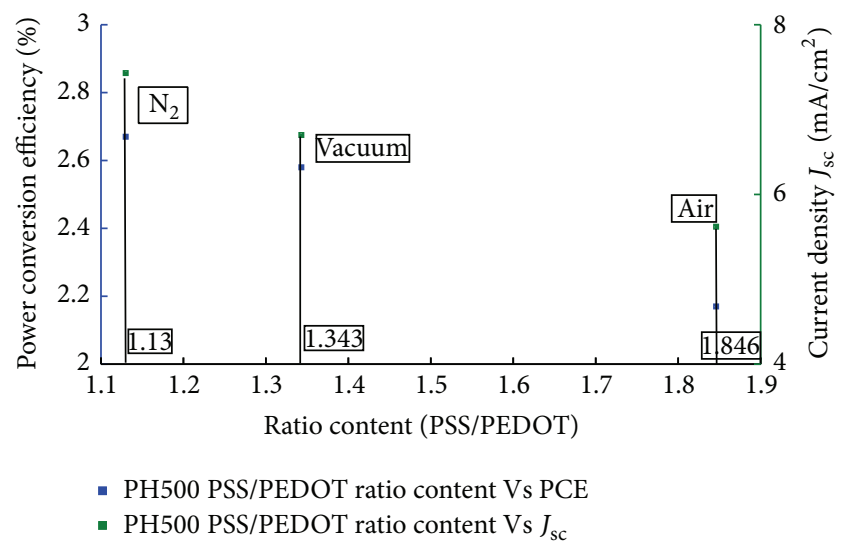

FIGURE 3: Plot showing the variation between the ratio of PSS to PEDOT content (obtained from XPS analysis) in PH500 measured at optimum annealing temperature in different atmospheres with the PCE and $J_{\mathrm{sc}}$ values of the OPV devices based on them.

annealing and it has strong correlation with PSS/PEDOT ratio. For PEDOT:PSS, the different drying dynamics can be also responsible for a change in orientation of the PEDOT grains within the film which can lead to changes in conductivity and surface property $[12,29,30]$ and this can also cause differences in conductivity characteristics in different atmospheres. The component variation of PEDOT and PSS has major influence on electrical behavior of the polymer film which was confirmed by our XPS study.

\section{Conclusion}

In conclusion we have evaluated the effect of PEDOT:PSS performance in response to annealing in different atmospheres and temperatures and also found out optimum conditions. The changes in behavior were analyzed with XPS technique. Although air is an easily processable and cost effective annealing atmosphere for PEDOT:PSS, it was found out to be reducing the electrical properties of the layer and hence performance of the OPV devices based on them. Vacuum atmosphere will contribute to appreciable electrical performance for the polymer during annealing but the condition is not achieved easily on commercial view. Annealing in $\mathrm{N}_{2}$ atmosphere for 1 hour at $220^{\circ} \mathrm{C}$ will change PSS/PEDOT ratio to 1.13 and exhibit superior electrical performance. Moreover the results from this study gives room for researchers to design the polymer blend in the favourable ratio to achieve good performance in any atmosphere of vacuum, air, and $\mathrm{N}_{2}$.

\section{Conflict of Interests}

The authors declare that there is no conflict of interests regarding the publication of this paper.

\section{Acknowledgments}

The authors thank Autosys Project no. 1082/31/2011 and Painettavaa Palautus Tekes Project no. 1116/31/2013 for partial funding of the research.

\section{References}

[1] T. D. Nielsen, C. Cruickshank, S. Foged, J. Thorsen, and F. C. Krebs, "Business, market and intellectual property analysis of polymer solar cells," Solar Energy Materials and Solar Cells, vol. 94, no. 10, pp. 1553-1571, 2010.

[2] M. Jørgensen, K. Norrman, and F. C. Krebs, "Stability/degradation of polymer solar cells," Solar Energy Materials and Solar Cells, vol. 92, no. 7, pp. 686-714, 2008.

[3] B. Augustine, R. Sliz, K. Lahtonen, M. Valden, R. Myllylä, and T. Fabritius, "Effect of plasma treated $\mathrm{Ag}$ /indium tin oxide anode modification on stability of polymer solar cells," Solar Energy Materials and Solar Cells, vol. 128, pp. 330-334, 2014.

[4] M. Jaiswal and R. Menon, "Polymer electronic materials: a review of charge transport," Polymer International, vol. 55, no. 12, pp. 1371-1384, 2006.

[5] Y. Min Nam, J. Huh, and W. Ho Jo, "Optimization of thickness and morphology of active layer for high performance of bulkheterojunction organic solar cells," Solar Energy Materials and Solar Cells, vol. 94, no. 6, pp. 1118-1124, 2010.

[6] K.-J. Kim, Y.-S. Kim, W.-S. Kang et al., "Inspection of substrate-heated modified PEDOT:PSS morphology for all spray deposited organic photovoltaics," Solar Energy Materials and Solar Cells, vol. 94, no. 7, pp. 1303-1306, 2010.

[7] L. Groenendaal, F. Jonas, D. Freitag, H. Pielartzik, and J. R. Reynolds, "Poly(3,4-ethylenedioxythiophene) and its derivatives: past, present, and future," Advanced Materials, vol. 12, no. 7, pp. 481-494, 2000.

[8] F. Jonas and G. Heywang, "Technical applications for conductive polymers," Electrochimica Acta, vol. 39, no. 8-9, pp. 13451347, 1994.

[9] S. K. M. Jönsson, J. Birgerson, X. Crispin et al., "The effects of solvents on the morphology and sheet resistance in poly(3,4ethylenedioxythiophene)-polystyrenesulfonic acid (PEDOTPSS) films," Synthetic Metals, vol. 139, no. 1, pp. 1-10, 2003.

[10] J. Hwang, F. Amy, and A. Kahn, "Spectroscopic study on sputtered PEDOT · PSS: role of surface PSS layer," Organic Electronics, vol. 7, no. 5, pp. 387-396, 2006.

[11] A. Elschner, S. Kirchmeyer, W. Lovenich, and U. Merker, PEDOT: Principles and Applications of Intrinsically Conductive Polymer, CRC Press, Boca Raton, Fla, USA, 2011.

[12] A. M. Nardes, M. Kemerink, M. M. de Kok, E. Vinken, K. Maturova, and R. A. J. Janssen, "Conductivity, work function, and environmental stability of PEDOT:PSS thin films treated with sorbitol," Organic Electronics, vol. 9, no. 5, pp. 727-734, 2008.

[13] L. S. C. Pingree, B. A. MacLeod, and D. S. Ginger, "The changing face of PEDOT:PSS films: Substrate, bias, and processing effects on vertical charge transport," Journal of Physical Chemistry C, vol. 112, no. 21, pp. 7922-7927, 2008.

[14] S. Kirchmeyer, K. J. Reuter, and J. Mater, "Scientific importance, properties and growing applications of poly(3,4ethylenedioxythiophene)," Journal of Materials Chemistry, vol. 15, no. 21, pp. 2077-2088, 2005.

[15] B. H. Fan, X. G. Mei, and J. Ouyang, "Significant conductivity enhancement of conductive poly(3,4- ethylenedioxythiophene): poly(styrenesulfonate) films by adding anionic surfactants into polymer solution," Macromolecules, vol. 41, no. 16, pp. 5971-5973, 2008.

[16] J. Huang, P. F. Miller, J. S. Wilson, A. J. de Mello, J. C. de Mello, and D. D. Bradley, "Investigation of the effects of doping 
and post-deposition treatments on the conductivity, morphology, and work function of poly(3,4-ethylenedioxythiophene)/ poly(styrene sulfonate) films," Advanced Functional Materials, vol. 15, no. 2, pp. 290-296, 2005.

[17] O. Ourida and B. M. Said, "Influence of the blend concentration of P3HT: PCBM in the performances of BHJ solar cells," Science Academy Transactions on Renewable Energy Systems Engineering and Technology, vol. 1, no. 3, pp. 90-92, 2011.

[18] W. Ma, C. Yang, X. Gong, K. Lee, and A. J. Heeger, “Thermally stable, efficient polymer solar cells with nanoscale control of the interpenetrating network morphology," Advanced Functional Materials, vol. 15, no. 10, pp. 1617-1622, 2005.

[19] C. J. Brabec, S. E. Shaheen, C. Winder, N. S. Sariciftci, and P. Denk, "Effect of LiF/metal electrodes on the performance of plastic solar cells," Applied Physics Letters, vol. 80, no. 7, pp. 1288-1290, 2002.

[20] S. Yang, X. Sun, Y. Zhang et al., "Enhancing the efficiency of polymer solar cells by modifying buffer layer with $\mathrm{N}, \mathrm{N}-$ dimethylacetamide," International Journal of Photoenergy, vol. 2014, Article ID 854749, 6 pages, 2014.

[21] H. Park, S. H. Lee, F. S. Kim, H. H. Choi, I. W. Cheong, and J. H. Kim, "Enhanced thermoelectric properties of PEDOT:PSS nanofilms by a chemical dedoping process," Journal of Materials Chemistry A, vol. 2, no. 18, pp. 6532-6539, 2014.

[22] G.-F. Wang, X.-M. Tao, J. H. Xin, and B. Fei, "Modification of conductive polymer for polymeric anodes of flexible organic light-emitting diodes," Nanoscale Research Letters, vol. 4, no. 7, pp. 613-617, 2009.

[23] A. A. Farah, S. A. Rutledge, A. Schaarschmidt, R. Lai, J. P. Freedman, and A. S. Helmy, "Conductivity enhancement of poly(3,4-ethylenedioxythiophene)-poly(styrenesulfonate) films post-spincasting," Journal of Applied Physics, vol. 112, no. 11, Article ID 113709, 2012.

[24] B. Friedel, P. E. Keivanidis, T. J. K. Brenner et al., "Effects of layer thickness and annealing of PEDOT:PSS layers in organic photodetectors," Macromolecules, vol. 42, no. 17, pp. 6741-6747, 2009.

[25] G. Greczynski, T. Kugler, and W. R. Salaneck, "Characterization of the PEDOT-PSS system by means of X-ray and ultraviolet photoelectron spectroscopy," Thin Solid Films, vol. 354, no. 1, pp. 129-135, 1999.

[26] Y. Kim, M. Shin, and H. Kim, "Annealing temperature effect of hole-collecting polymeric nanolayer in polymer solar cells," Macromolecular Research, vol. 16, no. 3, pp. 185-188, 2008.

[27] R. Sliz, Y. Suzuki, T. Fabritius, and R. Myllyla, "Influence of temperature on wetting properties of thin films in organic solar cells applications," Colloids and Surfaces A: Physicochemical and Engineering Aspects, vol. 443, pp. 182-187, 2014.

[28] Information regarding the boiling point of PEDOT:PSS, http://www.heraeus-clevios.com/media/webmedia_local/media/ datenblaetter/81076827_Clevios_PH_500_20101222.pdf.

[29] R. Kiebooms, A. Aleshin, K. Hutchison, F. Wudl, and A. Heeger, "Doped poly(3,4-ethylenedioxythiophene) films: thermal, electromagnetical and morphological analysis," Synthetic Metals, vol. 101, no. 1, pp. 436-437, 1999.

[30] P. A. Kralchevsky and N. D. Denkov, "Capillary forces and structuring in layers of colloid particles," Current Opinion in Colloid and Interface Science, vol. 6, no. 4, pp. 383-401, 2001. 

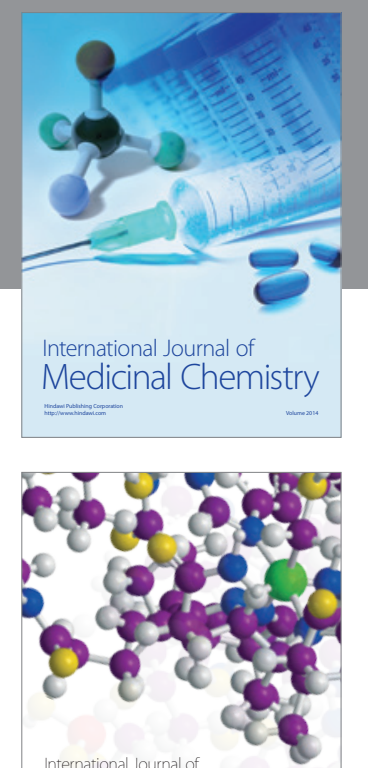

\section{Carbohydrate} Chemistry

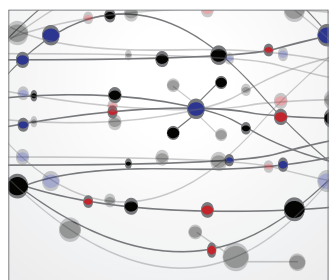

The Scientific World Journal
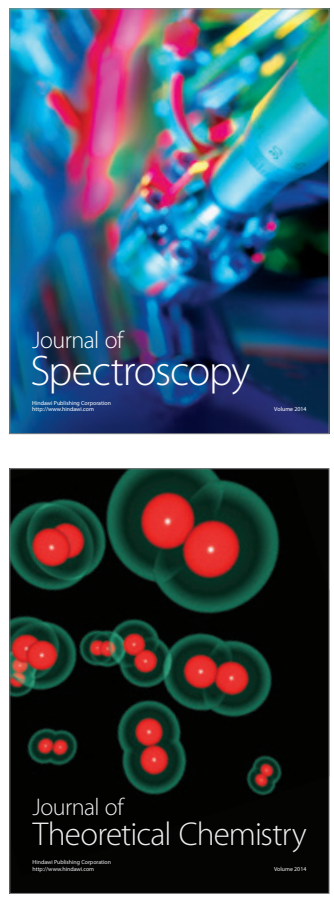
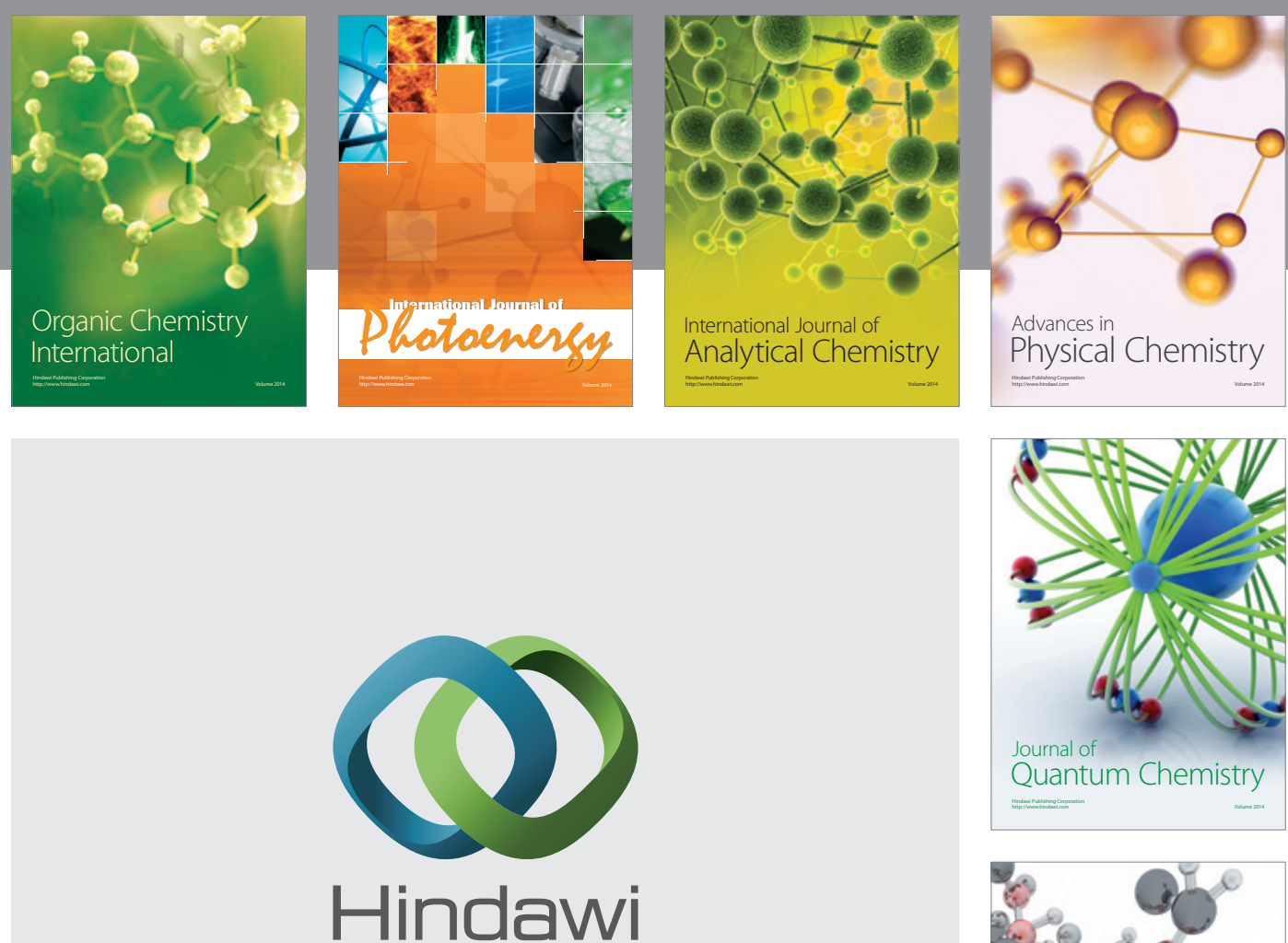

Submit your manuscripts at

http://www.hindawi.com

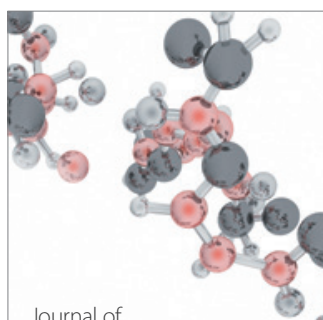

Analytical Methods

in Chemistry

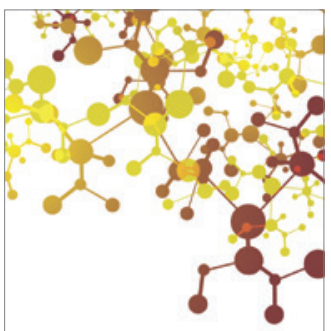

Journal of

Applied Chemistry

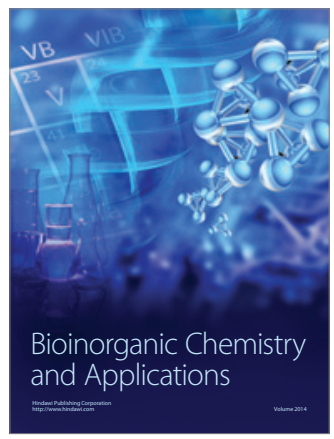

Inorganic Chemistry
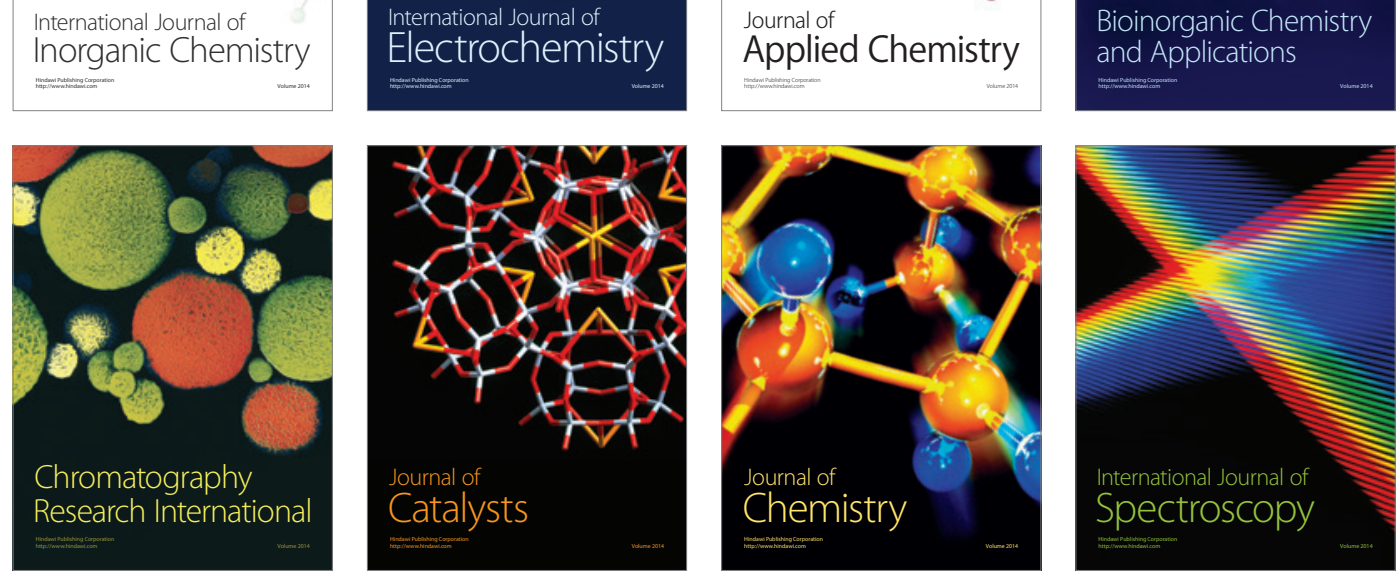